\title{
Unusual Multiple Recurrence of Lipschütz Ulcer of the Vulva in a Young Woman: Case Report and Review of the Literature
}

\author{
Carriero Carmine*, Schonauer Luca Maria, Loverro Giuseppe \\ Dept. of Biomedical Sciences and Human Oncology, Section Gynaecology, University of Bari, Bari (Italy).
}

Email address:

carmine.carriero@uniba.it (C. Carriero)

To cite this article:

Carriero Carmine, Schonauer Luca Maria, Loverro Giuseppe. Unusual Multiple Recurrence of Lipschütz Ulcer of the Vulva in a Young Woman: Case Report and Review of the Literature. Journal of Gynecology and Obstetrics. Vol. 3, No. 6, 2015, pp. 107-110. doi: $10.11648 /$ j.jgo.20150306.11

\begin{abstract}
Case: A case of 23-year-old woman, virgin, presenting a painful ulcerated vulvar lesion of the vestibular mucosa, with characteristics of Lipschütz ulcer, is reported. Lab tests showed no significant abnormalities, positivity for IgG of HSV1, rubeola, and VZV (with very high title: $2700 \mathrm{mUI} / \mathrm{ml}$ ), positivity for EBV IgG of VCA and EBNA components and IgM negative (indicating a past infection serologic profile). A moderate insufficiency of Vitamin D was found. A treatment with topical antibiotics and oral antinflammatory drugs was planned and healing was complete without scars in less than 2 weeks. During a period of 6 months the lesion relapsed twice, with the same benign course of the first episode. DISCUSSION: such homogeneous clinical pattern is related to a heterogeneous etiologic spectrum, in which Epstein-Barr virus appears somehow prevalent, but not exclusive, as demonstrated by review of the literature. It is important to have well in mind this differential diagnosis, as Lipschütz ulcer may be overestimated and treated as for other more alarming causes of genital ulceration, with more complicated and unnecessary diagnostic and therapeutic procedures. These four points must be stressed: (1) Acute mononucleosis should always be in a clinician's differential diagnosis of Acute Genital Ulcer (AGU); (2) Failure to consider causes other than genital aphthosis (Behçet) or herpes may expose patients and their family to unnecessary investigations, treatments, and stress; (3) The symptoms of AGU are essentially nonspecific; (4) The physiopathology and aetiology of nonherpetic AGU still constitute broadly unexplored research fields in which further prospective clinical and microbiological studies are needed. Moreover, according to the findings of the reported case, a recurrent Lipschutz ulcer of the vulva in a young women could be related to Herpes Simplex or Varicella Zoster virus.
\end{abstract}

Keywords: Vulva, Ulcus Vulvae Acutum, Lipschutz Ulcer, Recurrence, Varicella Zoster Virus

\section{Introduction}

"Ulcus vulvae acutum", i.e. acute ulcer of the vulva, was firstly described in a series of four cases of girls aged 14 to 17 by the Austrian dermatologist Benjamin Lipschütz, in 1913[1]. After successive reports[2-3], this syndrome was defined as a rapid onset ulceration on the vulvar skin or mucosa, often single and generally not more than three, associated with fever and inguinal painful lymphadenopathy, in girls or young women (age 14-20 years), without implication of possible sexually transmitted infections: often patients are not sexually active or even virgin (70\%). In most cases, the ulcer is located on the inner aspect of labia minora, labia majora, introitus, external urethral orifice or fourchette [4]. The natural course is generally benign, with spontaneous regression within few weeks and without scars [4-5]. Considering several case reports in the literature, this lesion has never shown a particular tendency to recur. We describe an unusual case of a young woman with a lesion that, according to clinical aspects, was definable as Lipschütz ulcer of the vulva, but, after regression in less than 2 weeks, recurred twice within a six-month-period.

\section{Case Report}

A 23-year-old woman, virgin, presenting ulcerated painful vulvar lesion of the vestibular mucosa and the posterior and inner part of the right labium minus (figure 1). The single ulcerated lesion presented sharp and not infiltrated edges, with an erythematous halo and a slightly swollen vulva. No 
fever or lymphadenopathy were reported. The patient did not complain of oral ulcers or other dermatologic abnormalities. The oral examination excluded the presence of aphthae or signs of stomatitis and Pathergy test was negative.
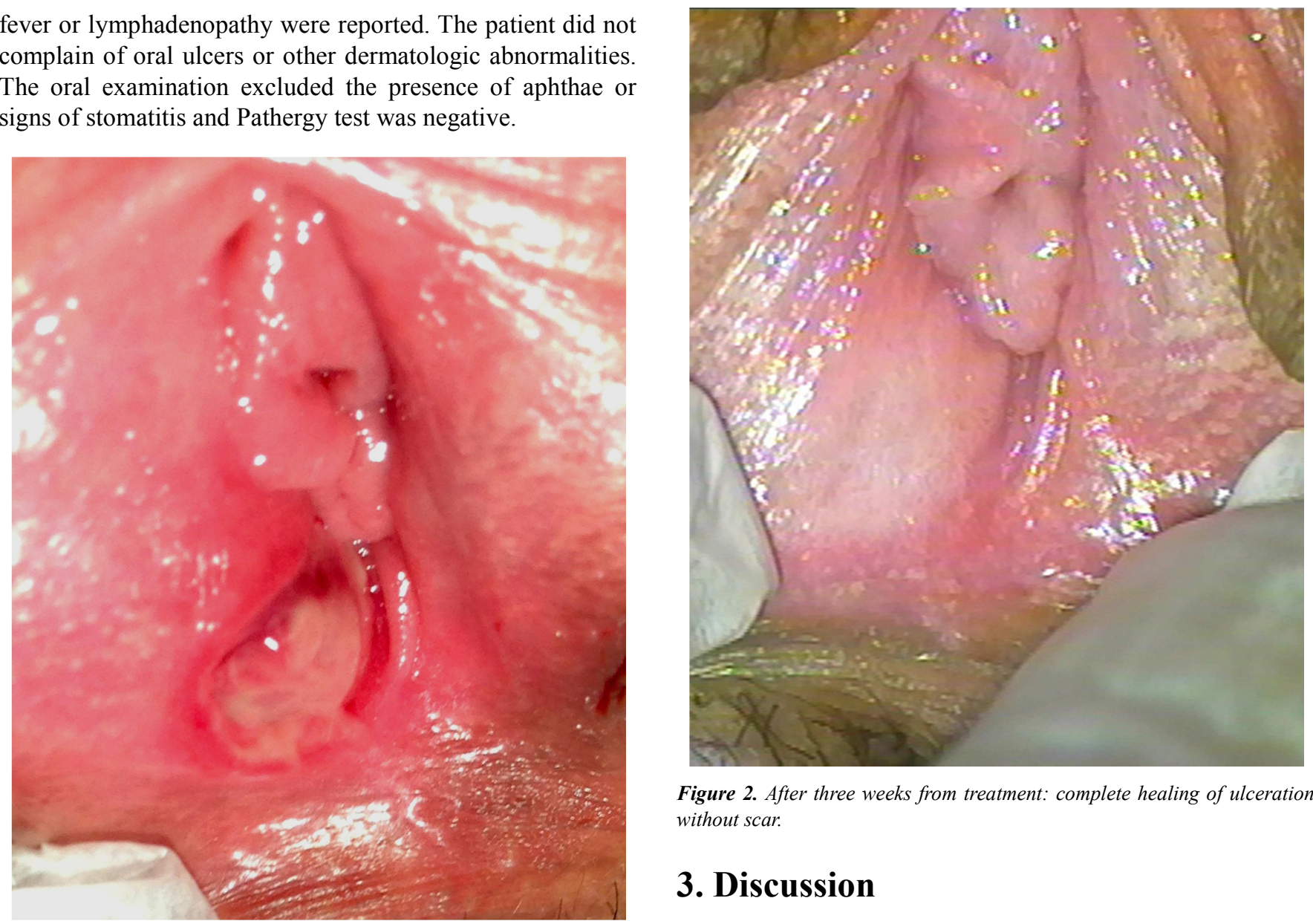

Figure 2. After three weeks from treatment: complete healing of ulceration without scar.

\section{Discussion}

Figure 1. Ulceration on the mucosa of the vestibule and on the posterior and inner part of the right labium minus.

Blood lab tests did not present abnormalities, apart from a very mild elevation of Alanine-aminotransferase (ALT): $43 \mathrm{U} / 1$, with max normal value being $40 \mathrm{U} / 1$. Serology was negative for Toxoplasma and CMV (cytomegalovirus). Acquired immunity (negative IgM and positive $\operatorname{IgG}$ ) was found for rubeola virus, HSV 1 (herpes simplex virus 1) and VZV (varicella zoster virus), the last with very high IgG title $(2700 \mathrm{mUI} / \mathrm{ml}$ compared with a normal positivity value $>120 \mathrm{mUI} / \mathrm{ml}$ ). In addition, IgG for Epstein Barr virus were positive for both EBNA (nuclear antigens) and VCA (viral capside antigens), indicating the antigenic profile of a past infection. Serological investigations were also negative for HIV, VDRL, HBsAg. Thyroid asset was normal, while Vitamin D resulted insufficient (25hydroxycholecalciferol was $18,3 \mathrm{ng} / \mathrm{ml}$ compared to acceptable value $>30 \mathrm{ng} / \mathrm{ml}$ ).

Topical treatment with antibiotic (fusidic acid cream) to avoid super infection and oral analgesic NSAIDs (Non steroidal anti-inflammatory drugs) were indicated. The lesion regressed completely without scar in 7-10 days (figure 2).

In a period of about 6 months the lesion relapsed twice, concomitantly with fever, flu-like symptoms and use of drugs. In both recurrences the ulcer regressed in few days with the same treatment and without complications, like the first episode.

Since the first description[1], the etiology of this condition has been very difficult to define: Lipschütz assumed that the disease was caused by autoinoculation with Bacillus crassus (later named as Doderlein's lactobacillus), while others ascribed generically the disease to poor hygiene of young women[3]. More recently this condition has been linked to many infective forms, mainly viral. Episodic reports refer about hypothetic association of ulcus vulvae acutum with Paramixovirus in a 21-year-old girl with bilateral parotitis[6], with Influenza A virus in a 13-year-old girl[7], with Salmonella typhi and parathyphi $A$ infection[8]. A case of Ulcus vulvae acutum with cold-agglutinin-positive, Mycoplasma-caused atypical pneumonia has been reported[9]. In a very recent series Mycoplasma pneumoniae has been recognized in one out of 12 cases of acute genital ulcers in nonsexually active young girls, while work-up failed to reveal a specific infectious or autoimmune etiology in the remaining 11 cases[10].

Another recent review of 13 pubertal girls with nonsexually related acute genital ulcer[11] revealed a heterogeneity of clinical and microbiological findings, but the final diagnosis was Epstein-Barr virus primary infection in 4 patients (31\%) and Behçet disease in 1 patient (8\%). No other infectious agents were detected in this series. Behçet disease is a well defined vulvar dermatosis, classified as Vasculopathic pattern in the 2006 ISSVD classification of vulvar dermatoses [12]. For the diagnosis of Behçet disease 
the major criteria of recurrent oral ulceration must be always present, accompanied by at least two out of four minor criteria, such as eye lesions, skin lesions, recurrent genital ulceration and positive skin Pathergy test[13]. Thus, a differential diagnosis between genuine Lipschütz ulcer and Behçet disease should not be too difficult [14].

In fact, the most common association of acute genital ulceration generally reported is with viral infections, mainly of family Herpesviridae: subfamily alpha: herpes simplex 1-2 (HSV) and Varicella zoster virus (VZV), subfamily beta: Cytomegalovirus (CMV) and subfamily gamma: EpsteinBarr virus (EBV).

While one of the most common causes of genital ulcer in sexually active women is HSV, and the primary infection of CMV is considered largely under recognized [15-16], in nonsexually related genital ulcerations the most commonly found viral infection is EBV[17-24]. In 1977 Brown \& Stenchever [17] published a case of a genital ulceration in a 14-year-old, with fever and headache, associated with mononucleosis. In 1984 Portnoy and coll. reported the recovery of the EpsteinBarr virus in genital ulcers [18]. Halvorsen and coll. in 2006 [25] made a review of 26 case reports in the literature of acute genital ulcerations in virgins or nonsexually active girls, with diagnosis of EBV infection, by serologic diagnosis of IgG and IgM for VCA (viral capside antigens) in most cases, while in 5 cases virus had also been identified from the ulcer by PCR or culture [17, 21, 24].

Considering this heterogeneity of etiological factors, which may include also (in sexually active girls) HIV and syphilis, and even ulcerative vulvitis of Reiter's syndrome [26], it is possible to suspect that several distinct nosological entities may have been reported under the entry Lipschütz's ulcer, thus further hampering the understanding of this syndrome. Fahri et al. [10] proposed to avoid this terminology and to define criteria to designate a peculiar clinical situation that requires prompt diagnosis and management, often in an emergency context: the first flare of Acute Genital Ulcer (AGU) in an immunocompetent patient without any context of sexually transmitted disease (STD) or aphthosis. These four points have been stressed by these Authors: (1) Acute mononucleosis should always be in a clinician's differential diagnosis of AGU, especially when there is no context of sexual transmission and no history of genital aphthosis. (2) Failure to consider causes other than genital aphthosis (Behçet) or herpes may expose patients and their family to unnecessary investigations, treatments, and stress. (3) The symptoms of AGU are essentially nonspecific; therefore, a systematic initial workup is required and should be clinically oriented. (4) The physiopathology and etiology of nonherpetic AGU still constitute broadly unexplored research fields in which further prospective clinical and microbiological studies are needed. [10]

The most recent reports of Lipschutz ulcer of the vulva confirm the difficult aetiological and clinical assessment of this condition. A large series from Brazil reports 33 cases of Lipschutz ulcer [27], about one third of 110 cases of vulvar ulcer seen during 5 years in a Vulvar Clinic: a microbiological possible cause was identified only in $9(27.3 \%)$ patients: CMV ( 3 cases), Mycoplasma pneumoniae (3 cases), EBV (2 cases) and PVB19 (1 case). Horie and coll. [28] report three consecutive cases of young women with Lipschutz ulcer associated with a recent Mycoplasma fermentans infection. Haidari and coll. [29] report the first case of influenza B virus and adenovirus infections associated with the presentation of Lipschutz ulcer. Finally, from Hungary, Kinyó and coll.[30] report two cases without a detectable infective cause, while both patients had partial IgA deficiency, therefore the Authors emphasize the possible role of local immunological mechanisms rather than several infectious agents in the development of this little-known disease.

In our reported case there are some adjunctive critical points that must be stressed: (1) the serologic results for EBV demonstrate the pattern of a past infection (positivity of IgG VCA and EBNA) and negativity of IgM, then acute infection by EBV does not seem the most plausible cause. (2) The significance of the very high detected title of VZV IgG cannot be easily weighed up, lacking in literature any report about correlation between VZV and acute genital ulcer, even if, differently from HSV, VZV can be better related to a nonsexually transmitted etiology, since the primary infection (varicella) is typical of pediatric age. (3) In our case the ulcer, after the first episode, recurred twice in a relatively short time period, the recurrence of Lipschütz ulcer is very unusual in literature, and this eventuality could be rather suggestive of herpes simplex or zoster disease. (4) Finally, the possible role of Vitamin D deficiency is not clear and it is impossible to make any evaluation of this finding.

\section{Conclusion}

Concluding, the clinical definition of Lipschütz ulcer leans on some well defined characteristics: one or few ulcerated lesions, painful, not infiltrated, with hyperemia and edema, with more or less fever and lymphadenopathy, in a young girl without sexual risk behavior or even virgin, with rapid regression and no scarring. However, such homogeneous clinical pattern is related to a heterogeneous etiologic spectrum, in which Epstein-Barr virus appears somehow prevalent, but not exclusive. For a differential diagnosis, initial workup may include complete blood cell count, bacterial culture, serologic test for syphilis, EBV, HIV. PCR assays for HSV and skin biopsy from an ulcer edge are only indicated if necessary, considering that for Lipschütz ulcer the histological examination is not of diagnostic value because findings are nonspecific: superficial edema and dilated capillaries with neutrophilic infiltration and ulceration. Diagnosis of Lipschütz ulcer is mainly clinical, after exclusion of other causes of vulvar ulcers: venereal and nonvenereal infections, noninfectious diseases, traumatic causes and malignant tumors. Treatment is based on topical and/or oral antibiotics and antinflammatory drugs, the condition is self-limited and healing occurs spontaneously, usually in 2 weeks. Recurrences are rare, but possible; in this eventuality they have a benign course, similar to the first episode. 
It is important to have well in mind this differential diagnosis, as patients with Lipschütz ulcers often are treated for herpes simplex or for other more alarming causes of genital ulceration, with more complicated treatments, without any real benefit [5].

\section{References}

[1] Lipschütz B. Uber eine eigenartige Geschwürsform des weiblichen Genitales (Ulcus vulvae acutum). Arch Dermatol Syph (Berlin). 1913; 114: 363-96.

[2] Zeitsch. F. Geburtsh. U. Gynak. Womans Clin 1947; 128: 30726.

[3] Berlin C. The pathogenesis of the so-called ulcus vulvae acutum. Acta Derm Venereol 1965; 45: 221-2.

[4] Bhat RM, Furtado S. Lipschutz ulcer. Indian J Sex Transm Dis 2007; 28: 106-7.

[5] Brinca A, Canelas MM, Carvalho MJ, Vieira R, Figueiredo A. Lipschütz ulcer (ulcus vulvae acutum) - a rare cause of genital lesion. An Bras Dermatol. 2012; 87(4): 622-4.

[6] Chanal J, Carlotti A, Laude H, Wallet-Faber N, Avril MF, Dupin N. Lipschütz genital ulceration associated with mumps. Dermatology. 2010; 221(4): 292-5.

[7] Wetter DA, Bruce AJ, MacLaughlin KL, Rogers RS 3rd. Ulcus vulvae acutum in a 13-year-old girl after influenza A infection. Skinmed. 2008; 7: 95-8.

[8] Pelletier F, Aubin F, Puzenat E, Deprez P, Blanc D, Estavoyer $\mathrm{JM}$, et al. Lipschütz genital ulceration: rare manifestation of paratyphoid fever. Eur J Dermatol. 2003;13:297-8.

[9] Korting GW, Hinterberger G. Ulcus vulvae acutum with coldagglutinin-positive, Mycoplasma-caused atypical pneumonia. Hautarzt. 1979; 30: 550-2.

[10] Rosman IS, Berk DR, Bayliss SJ, White AJ, Merritt DF. Acute genital ulcers in nonsexually active young girls: case series, review of the literature, and evaluation and management recommendations. Pediatr Dermatol. 2012; 29(2): 147-53.

[11] Farhi D, Wendling J, Molinari E, Raynal J, Carcelain G, Morand $\mathrm{P}$, et al. Non-sexually related acute genital ulcers in 13 pubertal girls: a clinical and microbiological study. Arch Dermatol. 2009; 145: 38-45.

[12] Lynch PJ, Moyal-Barracco M, Bogliatto F, Micheletti L, Scurry J. 2006 ISSVD classification of vulvar dermatoses: pathologic subsets and their clinical correlates. Journal of Reproductive Medicine. 2007; 52: 3-9.

[13] International Study Group for Behcet's Disease. Criteria for diagnosis of Behcet's disease. Lancet, 1990; 335: 1078-1080.

[14] Housmans S, Moerman P, Amant F, Koninckx Ph, Donders G, and Verguts J. Vulvar ulcers: a differential diagnosis between Behçet's disease and Lipschütz ulcus. Eur Clinics Obstet Gynaecol 2007, 3: 59-62.
[15] Martín JM, Godoy R, Calduch L, Villalon G, Jordá E. Lipschütz acute vulval ulcers associated with primary cytomegalovirus infection. Pediatr Dermatol. 2008; 25(1): 113-5.

[16] Huppert JS. Lipschutz ulcers: evaluation and management of acute genital ulcers in women. Dermatol Ther. 2010; 23(5): 533-40.

[17] Brown ZA, Stenchever MA. Genital ulceration and infectious mononucleosis: report of a case. Am J Obstet Gynecol 1977; 127: 673-674.

[18] Portnoy J, Ahronheim GA, Ghibu F, Clecner B, Joncas JH. Recovery of Epstein-Barr virus from genital ulcers. New Engl J Med. 1984; 311: 966-8.

[19] Wilson RW. Genital ulcer and Mononucleosis. Pediatr Infect Dis 1993; 12: 418 .

[20] Lampert A, Assier-Bonnet H, Chevallier B, Clerici T, Saiag P. Lipschütz's genital ulceration: a manifestation of Epstein Barr virus primary infection. Br J Dermatol 1996; 135: 663-5.

[21] Hudson LB, Periman SE. Necrotizing genital ulcerations in premenarcheal female with mononucleosis. Obstet Gynecol. 1998;92:185-7.

[22] Taylor S, Drake SM, Dedicoat M, Wood MJ. Genital ulcers associated with acute Epstein-Barr virus infection. Sex Transm Infect. 1998; 74(4): 296-7.

[23] Sisson BA, Glick L. Genital ulceration as a presenting manifestation of infectious mononucleosis. J Pediatr Adolesc Gynecol 1998; 11: 185-7.

[24] Cheng SX, Chapman MS, Margesson LJ, Birenbaum D. Genital ulcers caused by Epstein-Barr virus. $J$ Am Acad Dermatol. 2004; 51: 824-6.

[25] Halvorsen JA, Brevig T, Aas T, Skar AG, Slevolden EM, Moi $\mathrm{H}$. Genital ulcers as initial manifestation of Epstein-Barr virus infection: two new cases and a review of the literature. Acta Derm Venereol. 2006; 86(5): 439-42.

[26] Trĉko K, Beliĉ M, and Miljković J. Ulcus vulvae acutum. Acta Dermatoven APA 2007; 16: 174-6.

[27] Vieira-Baptista P, Lima-Silva J, Beires J, Martinez-de-Oliveira J. Lipschütz ulcers: should we rethink this? An analysis of 33 cases. Eur J Obstet Gynecol Reprod Biol. 2015 Aug 6. pii: S0301-2115(15)00253-5. [Epub ahead of print]

[28] Horie C, Kano Y, Takayo Mitomo T, Shiohara T. Possible Involvement of Mycoplasma fermentans in the Development of Nonsexually Acquired Genital Ulceration (Lipschütz Ulcers) in 3 Young Female Patients. JAMA Dermatol. Published online September 02, 2015.

[29] Haidari G, MacMahon E, Tong CY, White JA. Genital ulcers: it is not always simplex ... Int J STD AIDS. 2015 Jan; 26(1): $72-3$.

[30] Kinyó Á, Nagy N, Oláh J, Kemény L, Bata-Csörgő Z. Ulcus vulvae acutum Lipschütz in two young female patients. Eur $J$ Dermatol. 2014 May-Jun; 24(3): 361-4. 